\title{
Aspectos legais e conceituais de estudos epidemiológicos aplicados à avaliação de potencial malarígeno no Brasil
}

\author{
| ${ }^{1}$ Walter Santos de Araújo | \\ ${ }^{1}$ Departamento de Biologia Geral, Universidade Estadual de Montes Claros. Montes Claros-MG, Brasil (walterbioaraujo@gmail.com). \\ ORCID: 0000-0003-0157-6151 \\ Recebido em: 14/02/2019 \\ Aprovado em: 13/03/2019 \\ Revisado em: 12/07/2019
}

DOI: http://dx.doi.org/10.1590/S0103-73312019290302

Em países tropicais como o Brasil, o número de doenças que têm seu ciclo associado a insetos como vetores é grande (BRASIL, 2016). É o caso da malária, que historicamente é uma das zoonoses mais importantes no Brasil, sobretudo na Regiāo Norte do país (BARATA, 1995; BRASIL, 2010). A malária é causada por protozoários do gênero Plasmodium, que são naturalmente transmitidos por mosquitos do gênero Anopheles Meigen, 1818 (Culicidae, Diptera) (CONSOLI; LOURENÇO-DE-OLIVEIRA, 1994). O gênero Anopheles compreende cerca de 480 espécies no mundo (HARBACH, 2004), das quais 54 são registradas em diversas regióes do Brasil (CONSOLI; LOURENÇO-DE-OLIVEIRA, 1994; RODRIGUES et al., 2018).

Alguns estudos apontam que a implantação de empreendimentos potencialmente impactantes pode afetar a dinâmica populacional de anofelinos e, consequentemente, influenciar no risco de transmissão da malária (PÓVOA et al., 2009; PARENTE et al., 20I2). Por causa disso, a legislação ambiental brasileira estabelece a necessidade de Avaliação do Potencial Malarígeno (APM) durante os processos de licenciamento ambiental em regióes endêmicas de malária (por exemplo, a Portaria no 01/2014 MS/ SVS). Nesse sentido, compreender os aspectos legais e metodológicos dos estudos de potencial malarígeno e o contexto em que se inserem pode oferecer uma valiosa contribuição para programas de controle de malária no Brasil. 
A Portaria no 01/2014 MS/SVS preconiza que todos os empreendimentos em áreas de risco ou endêmica para malária devem realizar a APM como requisito para a obtenção de licenças ambientais e atestados sanitários. A APM compreende o diagnóstico detalhado da situação epidemiológica dos municípios influenciados, visando avaliar os riscos potenciais de aumento dos casos de malária em decorrência das intervençóes causadas pelos empreendimentos em licenciamento. Nesse sentido, a Portaria no 01/2014 MS/SVS estabelece os procedimentos metodológicos para embasar os estudos epidemiológicos e entomológicos durante a APM.

Conforme estabelece a Portaria no 01/2014 MS/SVS, o perfil epidemiológico da malária deve ser analisado para cada município sob influência do empreendimento em licenciamento. Essas informaçóes podem ser obtidas por meio de dados oficiais dos órgãos de saúde locais ou na base de dados do Sistema de Informação de Vigilância Epidemiológica do Ministério da Saúde (SIVEP-malária). Dentre os dados epidemiológicos que devem ser analisados, estão o número de casos por ano, a Incidência Parasitária Anual (IPA), a distribuição de casos por sexo e faixa etária e o percentual de malária falciparum em relação ao total de casos de malária.

Além do perfil epidemiológico, também se faz necessário o levantamento entomológico durante os estudos de APM. A Portaria no 45/2007 MS/SVS estabelece as atividades mínimas para levantamento entomológico, dentre as quais estão a realização de coletas das formas imaturas e aladas dos anofelinos e a identificação, dentro da área delimitada para o estudo, dos criadouros potenciais para os vetores. Já a Portaria no 01/2014 MS/SVS define que a amostragem deve ser feita em três campanhas distribuídas nos períodos do ano correspondentes à maior densidade anofélica, sendo uma amostragem no início do período chuvoso e outra no final, e também uma captura na época de menor pluviosidade. O levantamento entomológico visa identificar a ocorrência prévia de potenciais vetores da malária e subsidiar os planos de controle dos vetores na região estudada.

Do ponto de vista legal, a APM é imprescindível para a emissão do Laudo de Potencial Malarígeno (LAPM), que serve como base para a elaboração do Plano de Ação de Controle de Malária (PACM), que por sua vez é necessário para a emissáo do Atestado de Condição Sanitária (ATCS) do empreendimento (Portaria no 01/2014 MS/SVS). Assim, a APM não é apenas um trâmite burocrático para o licenciamento ambiental, mas também é uma importante ferramenta para se diagnosticar e controlar a disseminação da malária em regiôes impactadas por empreendimentos ambientais. 
Por exemplo, o PACM, construído com base na APM, é um documento elaborado e financiado pelo responsável do empreendimento em processo de licenciamento, com consulta e avaliação dos entes de saúde competentes, fundamentado nas diretrizes do Programa Nacional de Controle da Malária (PNCM) do Ministério da Saúde. Nesse documento são estabelecidas as estratégias de mitigação e controle de vetores, que são fundamentais para se diminuir os riscos de contaminação com a malária. Por esse motivo, a APM, o PACM e todos os produtos decorrentes dos estudos de malária devem ser feitos de maneira técnica e responsável, e não devem de maneira nenhuma ser fruto de interesses escusos ou partidários, visando assim ao bem comum e à saúde coletiva das populaçóes de regiōes impactadas.

\section{Referências}

BARATA, R. C. B. Malaria in Brazil: trends in the last ten years. Cadernos de Saúde Pública, v. 11, n. 1, p. 128-136, 1995.

BRASIL. Ministério da Saúde. Guia prático de tratamento da malária no Brasil. Brasília: Ministério da Saúde, Secretaria de Vigilância em Saúde, Departamento de Vigilância Epidemiológica, 2010.

. Ministério da Saúde. Manual de vigilância, prevenção e controle de zoonoses. Brasília: Ministério da Saúde, Secretaria de Atenção à Saúde, Departamento de Atenção Básica, 2016.

CONSOLI, R. A. G. B.; LOURENÇO-DE-OLIVEIRA, R. Principais mosquitos de importância sanitária no Brasil. Rio de Janeiro: Fiocruz, 1994.

HARBACH, R. E. The classification of genus Anopheles (Diptera: Culicidae): a working hypothesis of phylogenetic relationships. Bulletin of Entomological Research, v. 95, n. 6, p. 537$553,2004$.

PARENTE, A. T.; SOUZA, E. B.; RIBEIRO, J. B. M. A ocorrência de malária em quatro municípios do estado do Pará, de 1988 a 2005, e sua relação com o desmatamento. Acta Amazonica, v. 42, n. 1, p. 41-48, 2012.

PÓVOA, M. M. et al. Risco de transmissão de malária humana em área de implantação de projeto de prospecção mineral, município de Juruti, estado do Pará. Revista de Patologia Tropical, v. 38, n. 2, p. 93-102, 2009.

RODRIGUES, P. T. et al. Human migration and the spread of malaria parasites to the New World. Scientific Reports, v. 8, n. 1993, p. 1-13, 2018. 